Research article

\title{
Genetic Diversity and Relationships of Neolamarckia cadamba (Roxb.) Bosser progenies through cluster analysis
}

\section{Preethi Shree, N. Krishnakumar* and K. T. Parthiban}

Forest College and Research Institute, Tamil Nadu Agricultural University, Mettupalayam, Tamil Nadu, India *Corresponding Author: krishna.forest@ gmail.com

[Accepted: 26 April 2018]

\begin{abstract}
Genetic diversity analysis was conducted for biometric attributes in 20 progenies of Neolamarckia cadamba. The application of $\mathrm{D}^{2}$ clustering technique in Neolamarckia cadamba genetic resources resolved the 20 progenies into five clusters. The maximum intra cluster distance was shown by the cluster II. The maximum inter cluster distance was recorded between cluster III and $\mathrm{V}$ which indicated the presence of wider genetic distance between Neolamarckia cadamba progenies. Among the growth attributes, volume $(36.84 \%)$ contributed maximum towards genetic divergence followed by bole height, basal diameter, tree height, number of branches in Neolamarckia cadamba progenies.
\end{abstract}

Keywords: Genetic diversity - Cluster analysis - Intra cluster distance - Genetic distance.

[Cite as: Preethi Shree M, Krishnakumar N \& Parthiban KT (2018) Genetic Diversity and Relationships of Neolamarckia cadamba (Roxb.) Bosser progenies through cluster analysis. Tropical Plant Research 5(1): 107115]

\section{INTRODUCTION}

Global demand for wood is increasing at an annual rate of 1.7 percent (Parthiban 2016) At the same time, planted forest resources are insufficient to meet current demands. The scope for expansion of forested area is limited (Gregory et al. 2002). This trend creates economic pressure that encourages the commercial exploitation of natural forests unless supply can be increased through the establishment of high yielding plantations. The current supply of raw materials for industries like pulpwood, plywood, furniture and matchwood energy in the state is far behind the demand. Hence, to meet the growing raw material requirement and also to subserve the 1988 National Forest Policy Guidelines of Indian Government and to keep pace with these progressive developmental changes in the country, the industries must expand sharply its plantation programme. However, considering the acute shortage of suitable raw material, the industries have to establish a plantation of suitable species with tree improvement programme to achieve maximum yield within a short rotation period. This besides, choice of alternative tree species to meet the raw material requirement of industries is the need of the hour. Neolamarckia cadamba is one such alternative species suitable for pulpwood, plywood, matchwood and also in pencil industry.

In India both domestic and international market, the timber supply is facing a severe shortage. It is estimated that the demand for timber is likely to grow from 58 million cubic meters in 2005 to 153 million cubic meters in 2020. The wood supply is increased in past two decades from 29 million cubic meters in 2000 to 60 million cubic meters in 2020. The shortfall of 93 million cubic meters should be met by import from the international market. The productivity of timber in India is only $0.7 \mathrm{cu} \mathrm{m}^{-1} \mathrm{ha}^{-1}$ year ${ }^{-1}$ whereas the world average is $2.1 \mathrm{cu} \mathrm{m}^{-1}$ $\mathrm{ha}^{-1}$ year $^{-1}$ (Lal 2011). The supply of timber is mainly from forest plantations and wood production is showing a negative growth rate. In the absence of adequate supply from domestic sources, the nation has to depend heavily on imports to meet its demand for timber. This will increase the nation's forest footprint, particularly in South East Asia. In order to minimize the forest footprint, we need to encourage sustainable consumption of timber by promoting farm forestry. The demand gap should be bridged by increasing domestic production by introducing fast growing timber species with a short rotation like Neolamarckia cadamba.

For any tree improvement programme, determination of the species, or geographic source within species, amount, kind and cause of variation within the species are very important initial steps (Zobel \& Talbert 1984). 
Abundant variation is available in trees in nature, which the foresters can tap and use it to get the maximum improvement in a short span of time. Information from field experiments is very valuable because assessed adaptive genetic variation is still the best input for breeding and conservation activities (Zobel 1971). However, variation studies using biometric traits in Neolamarckia cadamba is dismally modest and demand intensive research.

The genetic diversity existing in the population will help to generate a rich base population for initiating proper selection (Zobel 1981). After clustering, the superior group or individual may directly be utilized for raising commercial plantation for meet out industrial wood demand. Determination of genetic diversity through mahalanobis $\mathrm{D}^{2}$ analysis in Neolamarckia cadamba has not been attempted so far and thus underscores investigation.

\section{MATERIALS AND METHODS}

The experimental materials for this study consisted of 20 genotypes of Neolamarckia cadamba selected from various locations of India (Table 1). The progeny evaluation experiments were carried out in the field of Forest College and Research Institute, Tamil Nadu Agricultural University, Mettupalayam ( $\left.11^{\circ} 19^{\prime} \mathrm{N}, 76^{\circ} 56^{\prime} \mathrm{E}\right), 300 \mathrm{~m}$. a.m.s.1., $800 \mathrm{~mm}, \mathrm{pH}$ 7.1) during 2012-2013.

Table 1. Location details of Neolamarckia cadamba genetic resources.

\begin{tabular}{lllrrr}
\hline Location & Genotype & State & Latitude & Longitude & Altitude (m) \\
\hline Tripura & FCRIK1 & Tripura & $23^{\circ} 49^{\prime}$ & $91^{\circ} 17^{\prime}$ & 78 \\
Khowai & FCRIK2 & Tripura & $24^{\circ} 04^{\prime}$ & $91^{\circ} 36^{\prime}$ & 46 \\
Tripura & FCRIK3 & Tripura & $23^{\circ} 55^{\prime}$ & $91^{\circ} 50^{\prime}$ & 89 \\
Mettupalayam & FCRIK4 & Tamil Nadu & $11^{\circ} 17^{\prime}$ & $76^{\circ} 56^{\prime}$ & 330 \\
Assam & FCRIK5 & Assam & $26^{\circ} 33^{\prime}$ & $90^{\circ} 26^{\prime}$ & 69 \\
Assam & FCRIK6 & Assam & $26^{\circ} 33^{\prime}$ & $90^{\circ} 26^{\prime}$ & 69 \\
Coimbatore & FCRIK7 & Tamil Nadu & $11^{\circ} 17^{\prime}$ & $76^{\circ} 56^{\prime}$ & 330 \\
Coimbatore & FCRIK8 & Tamil Nadu & $11^{\circ} 17^{\prime}$ & $76^{0} 56^{\prime}$ & 330 \\
Coimbatore & FCRIK9 & Tamil Nadu & $11^{\circ} 17^{\prime}$ & $76^{0} 56^{\prime}$ & 330 \\
Coimbatore & FCRIK10 & Tamil Nadu & $11^{\circ} 17^{\prime}$ & $76^{\circ} 56^{\prime}$ & 330 \\
Dapoli & FCRIK11 & Maharashtra & $17^{\circ} 45^{\prime}$ & $73^{\circ} 11^{\prime}$ & 175 \\
Maharashtra & FCRIK12 & Maharashtra & $21^{\circ} 08^{\prime}$ & $79^{\circ} 05^{\prime}$ & 313 \\
Tirupathi & FCRIK13 & Andhra Pradesh & $13^{\circ} 37^{\prime}$ & $79^{\circ} 25^{\prime}$ & 155 \\
Andhra Pradesh & FCRIK14 & Andhra Pradesh & $13^{\circ} 37^{\prime}$ & $79^{\circ} 25^{\prime}$ & 155 \\
Hyderabad & FCRIK15 & Andhra Pradesh & $17^{\circ} 22^{\prime}$ & $78^{\circ} 29^{\prime}$ & 502 \\
Andhra Pradesh & FCRIK16 & Andhra Pradesh & $17^{\circ} 22^{\prime}$ & $78^{\circ} 29^{\prime}$ & 502 \\
Karnal & FCRIK17 & Haryana & $29^{\circ} 41^{\prime}$ & $76^{\circ} 59^{\prime}$ & 251 \\
Haryana & FCRIK18 & Haryana & $29^{\circ} 41^{\prime}$ & $76^{0} 59^{\prime}$ & 251 \\
Thrissur & FCRIK19 & Kerala & $10^{\circ} 31^{\prime}$ & $79^{\circ} 13^{\prime}$ & 54 \\
Bangalore & FCRIK20 & Karnataka & $12^{\circ} 58^{\prime}$ & $77^{\circ} 35^{\prime}$ & 910 \\
\hline
\end{tabular}

\section{Species description}

$\begin{array}{lll}\text { Common name } & : & \text { Kadam } \\ \text { Species } & : & \text { Neolamarckia cadamba (Roxb.) Bosser } \\ \text { Family } & : & \text { Rubiaceae }\end{array}$

\section{Botanical features}

Neolamarckia cadamba is a large tree with a broad umbrella-shaped crown and straight cylindrical bole. The tree may reach a height of $45 \mathrm{~m}$ with a stem diameter of 100-160 cm and sometimes it has a small buttress up to $2 \mathrm{~m}$ high. The bark is grey, smooth and very light in young trees, but rough and longitudinally fissured in old trees. The branches spread horizontally and drop at the tip. The leaves are glossy green, opposite, simple sessile to petiolate, ovate to elliptical $(15-50 \mathrm{~cm}$ long by $8-25 \mathrm{~cm}$ wide). In young fertilised trees, the leaves are much larger, subordinate at the base and acuminate at apex; the stipules are interpetiolar, narrowly triangular and deciduous. The fruitlets are numerous, somewhat fleshy, with their upper parts containing 4 hollow or solid structures. The fruit contains approximately 8000 seeds with fleshy yellow-orange infructescence; small and fleshy capsules closely packed together. The seeds somewhat are trigonal or irregular shaped, not winged (Martawijaya et al. 1989). It is lightweight hardwood. The heartwood is not clearly different from sapwood. The heartwood is visually white with a yellow tinge darkening to creamy yellow (Soerianegara \& Lemmens 1993). 
Determination of genetic diversity

The Biometric data recorded during $32 \mathrm{MAP}$ in Neolamarckia cadamba progeny evaluation trial were used for diversity analysis (Table 2). The $\mathrm{D}^{2}$ statistics was adopted for the estimation of genetic divergence (Mahalanobis 1928). Using $\mathrm{D}^{2}$ statistical results, the clustering of progenies was done.

Table 2. Progeny evaluation of (32 MAP) in Neolamarckia cadamba.

\begin{tabular}{lrrrrrrr}
\hline $\begin{array}{l}\text { Name of the } \\
\text { progenies }\end{array}$ & $\begin{array}{r}\text { Tree } \\
\text { height }\end{array}$ & $\begin{array}{r}\text { Diameter } \\
\text { at Breast } \\
\text { Height }\end{array}$ & $\begin{array}{r}\text { Basal } \\
\text { Diameter }\end{array}$ & $\begin{array}{r}\text { Number of } \\
\text { branches }\end{array}$ & $\begin{array}{r}\text { Bole } \\
\text { height }\end{array}$ & $\begin{array}{r}\text { Crown } \\
\text { length }\end{array}$ & Volume \\
\hline FCRIK1 & 5.25 & 29.58 & $47.72^{*}$ & 24.0 & 2.25 & 3.00 & 0.036 \\
FCRIK2 & 5.38 & 26.45 & 39.12 & 30.2 & 2.09 & 3.29 & 0.036 \\
FCRIK3 & 5.71 & 26.25 & $47.10^{*}$ & 28.7 & 2.20 & 3.51 & 0.034 \\
FCRIK4 & 5.40 & 26.48 & 40.87 & 33.5 & 2.34 & 3.06 & 0.029 \\
FCRIK5 & 5.44 & 28.53 & 43.62 & 33.7 & 2.28 & 3.16 & 0.033 \\
FCRIK6 & 5.76 & 26.05 & 41.92 & 30.5 & 2.53 & 3.24 & 0.031 \\
FCRIK7 & $6.69^{*}$ & $32.45^{*}$ & $47.85^{*}$ & $42.5 *$ & $2.68^{*}$ & $4.01 *$ & $0.059^{* *}$ \\
FCRIK8 & 4.84 & 22.35 & 35.37 & 24.2 & 2.14 & 2.70 & 0.021 \\
FCRIK9 & 5.10 & 25.55 & 36.52 & 26.0 & 2.28 & 2.83 & 0.025 \\
FCRIK10 & 4.84 & 23.55 & 33.85 & 24.5 & 2.11 & 2.73 & 0.020 \\
FCRIK11 & 5.31 & 26.83 & 37.77 & 28.7 & 2.30 & 3.01 & 0.030 \\
FCRIK12 & 5.76 & 27.33 & 38.10 & 32.5 & 2.29 & 3.48 & 0.033 \\
FCRIK13 & $6.33 *$ & 28.00 & 42.25 & 31.0 & 2.21 & $4.11^{* *}$ & 0.035 \\
FCRIK14 & 5.29 & $32.40^{*}$ & 42.27 & 32.2 & 2.28 & 3.01 & 0.045 \\
FCRIK15 & 5.13 & 23.10 & 36.45 & 30.0 & 2.18 & 2.95 & 0.021 \\
FCRIK16 & $6.36^{*}$ & 28.90 & 50.20 & $40.0 *$ & 2.31 & $4.05^{*}$ & 0.045 \\
FCRIK17 & 5.55 & $32.43 *$ & 40.45 & $40.5 *$ & $2.65 *$ & 2.90 & 0.048 \\
FCRIK18 & 5.73 & 29.85 & 47.17 & 39.5 & 2.21 & 3.51 & 0.038 \\
FCRIK19 & 5.58 & 28.38 & 40.62 & 31.2 & 2.16 & 3.41 & 0.033 \\
FCRIK20 & 3.89 & 17.58 & 27.65 & 23.5 & 2.18 & 1.71 & 0.013 \\
Mean & $\mathbf{5 . 4 7}$ & $\mathbf{2 7 . 1 0}$ & $\mathbf{4 0 . 8 4}$ & $\mathbf{3 1 . 3}$ & $\mathbf{2 . 2 8}$ & $\mathbf{3 . 1 8}$ & $\mathbf{0 . 0 3 3}$ \\
SEd & $\mathbf{0 . 4 0}$ & $\mathbf{2 . 5 6}$ & $\mathbf{3 . 1 3}$ & $\mathbf{4 . 3 7}$ & $\mathbf{0 . 1 8}$ & $\mathbf{0 . 3 9}$ & $\mathbf{0 . 0 0 8}$ \\
CD (p= 0.05) & $\mathbf{0 . 8 1}$ & $\mathbf{5 . 1 3}$ & $\mathbf{6 . 2 8}$ & $\mathbf{8 . 6 8}$ & $\mathbf{0 . 3 6}$ & $\mathbf{0 . 7 7}$ & $\mathbf{0 . 0 1 7}$ \\
CD (p= 0.01) & $\mathbf{1 . 1 5}$ & $\mathbf{6 . 8 4}$ & $\mathbf{8 . 3 6}$ & $\mathbf{9 . 6 5}$ & $\mathbf{0 . 4 9}$ & $\mathbf{1 . 0 3}$ & $\mathbf{0 . 0 2 3}$ \\
\hline
\end{tabular}

$D^{2}$ statistics

The $\mathrm{D}^{2}$ statistics was carried out using the traits viz., plant height, basal diameter and volume index. The mean squares and the mean products were estimated between groups and within components by one-way analysis of variance, covariance and the significance were tested at progeny level. A variance - covariance was formed from the above and subjected to pivotal condensation to obtain the linear function for the transformation of character mean values (x) to a set of independent variables (uncorrected mean) value (y).

The difference between any two mean values for each pair of progeny was squared and added to give the $\mathrm{D}^{2}$ values. For each character Cumulative $\mathrm{D}^{2}$ values in all the possible combination of progeny were estimated.

Where,

$$
\begin{aligned}
& \mathrm{y}_{1}=\mathrm{x}_{1} \\
& \mathrm{y}_{2}=\mathrm{x}_{2}-\mathrm{a}_{2} \mathrm{x}_{1} \\
& \mathrm{y}_{3}=\mathrm{x}_{3}-\mathrm{a}_{32} \mathrm{y}_{2}-\mathrm{a}_{31} \mathrm{y}_{1} \\
& \mathrm{yp}=\mathrm{xp}-\mathrm{a}_{\mathrm{pp}-1} \mathrm{y}_{\mathrm{p}-1} \ldots . . \mathrm{ap}_{1} \mathrm{y}_{1}
\end{aligned}
$$

$$
\begin{aligned}
& \mathrm{x}_{1}=\text { normalized variables } \\
& \mathrm{a}_{\mathrm{ij}}=\mathrm{b}_{\mathrm{ij}} / \mathrm{v}\left(\mathrm{y}_{\mathrm{j}}\right) \mathrm{S}<-1 \\
& \mathrm{v}(\mathrm{yj})=\lambda \sum \mathrm{a}(\mathrm{ji}) \text { bij }-\mathrm{bij}=\lambda \mathrm{ij}-1 / \text { atbt } \\
& \lambda \mathrm{ij}=\text { covariance of } \mathrm{i} \text { and } \mathrm{j}^{\mathrm{t}}=\mathrm{ji}
\end{aligned}
$$

All possible [n (n-1)/2], $\mathrm{D}^{2}$ values were calculated by taking sum of difference between pair of corresponding ' $\mathrm{y}$ ' values taking two progenies at a time.

\section{Determination of clusters or grouping}

The progenies were grouped into different clusters using 'GENRES' statistical package on the basis of $\mathrm{D}^{2}$ values according to Tocher's method as suggested by Rao (1952). 


\section{Tocher's method}

All the [n (n-1)/2] X D ${ }^{2}$ values were clustered by using Tocher's method (Rao 1952).

\section{Average intra and inter cluster distances}

Intra and inter cluster relationships were studied on the completion of clustering analysis and the relationship between clusters and their distances were represented. The average intra cluster distances was measured using the formula

$$
\mathrm{D}^{2}=\mathrm{D}_{1}^{2} / \mathrm{n}
$$

Where $\mathrm{D}^{2}$ was the sum of distances between all possible combinations of the progeny included in a cluster whereas the average inter cluster divergences were arrived by taking into consideration of all the component $\mathrm{D}^{2}$ values possible among the numbers of the two clusters. Then the genetic distance ' $\mathrm{D}$ ' between the clusters were obtained from the square root of the average $\mathrm{D}^{2}$ values.

\section{RESULT}

\section{Genetic divergence}

The mean values were transformed into standardized uncorrelated mean values. The $\mathrm{D}^{2}$ values were computed for all positive pairs. 20 progenies of Neolamarckia cadamba were placed under five clusters on the basis of Mahalanobis $\mathrm{D}^{2}$ clustering techniques.

\section{Cluster components}

The clustering pattern revealed that the 20 progenies were resolved into five different clusters. The cluster I constituted 8 progenies viz., FCRIK1, FCRIK2, FCRIK3, FCRIK4, FCRIK5, FCRIK6, FCRIK9 and FCRIK10; whereas cluster II consisted of 6 progenies FCRIK8, FCRIK11, FCRIK12, FCRIK13, FCRIK14 and FCRIK15; Cluster III consisted 4 progenies FCRIK7, FCRIK16, FCRIK18 and FCRIK19; Cluster IV consisted 1 progenies FCRIK 17; Cluster V consisted 1 progeny FCRIK20 (Table 3).

Table 3. Clustering pattern of Neolamarckia cadamba for biometric attributes.

\begin{tabular}{lcl}
$\begin{array}{l}\text { Cluster } \\
\text { No. }\end{array}$ & $\begin{array}{c}\text { Number of } \\
\text { progenies }\end{array}$ & \multicolumn{1}{c}{ Members } \\
\hline I & 8 & FCRIK1,FCRIK2,FCRIK3,FCRIK4,FCRIK5,FCRIK6,FCRIK9, FCRIK10 \\
II & 6 & $\begin{array}{l}\text { FCRIK8, FCRIK11,FCRIK12,FCRIK13, } \\
\text { FCRIK14,FCRIK15 }\end{array}$ \\
III & 4 & FCRIK7,FCRIK16,FCRIK18,FCRIK19, \\
IV & 1 & FCRIK17 \\
V & 1 & FCRIK20 \\
\hline
\end{tabular}

Intra and inter cluster average distance

The average inter and intracluster $\mathrm{D}^{2}$ and $\mathrm{D}$ values among the five clusters are presented in table 4 . Intra and inter cluster ranged from 0.00 to 2.69 and 6.40 to 29.79 respectively. Intracluster distance maximum in cluster II (2.69) with seven accessions and minimum in cluster IV and V (0.00) with one accession respectively. Highest inter cluster was between cluster III and V (29.795), followed by cluster IV and V (27.528) suggesting that there is a wide genetic diversity between these groups. The minimum inter cluster distance was between cluster I and II (7.170).

Table 4. Intra (diagonal) and inter cluster $\mathrm{D}^{2}$ and $\mathrm{D}$ (parantheses) values of Neolamarckia cadamba for biometric attributes.

\begin{tabular}{lccccc}
\hline Cluster & $\mathbf{1}$ & $\mathbf{2}$ & $\mathbf{3}$ & $\mathbf{4}$ & $\mathbf{5}$ \\
\hline I & 6.406 & 7.170 & 7.839 & 17.097 & 19.167 \\
& $(2.531)$ & $(2.678)$ & $(2.800)$ & $(4.135)$ & $(4.378)$ \\
II & & 7.283 & 7.651 & 11.914 & 20.490 \\
& & $(2.699)$ & $(2.766)$ & $(3.452)$ & $(4.527)$ \\
III & & 5.413 & 15.707 & 29.795 \\
& & $(2.327)$ & $(3.963)$ & $(5.458)$ \\
IV & & & 0.000 & 27.528 \\
& & & $(0.000)$ & $(5.247)$ \\
V & & & & 0.000 \\
& & & & & $(0.000)$ \\
\hline
\end{tabular}




\section{Cluster mean performance}

The cluster mean for the traits was estimated and furnished in the table 5. Cluster mean expressed significant variation among clusters for all traits. The members in cluster III showed the highest performance of 5.88 for tree height followed by cluster II (5.62) while, the minimum was observed for the cluster V (3.88). The maximum cluster mean of 32.42 was observed for diameter at breast height in cluster III whereas the least cluster mean for diameter at breast height (17.57) was exhibited by the cluster V. The maximum cluster mean of 46.0 was observed for basal diameter in cluster III whereas the least cluster mean for basal diameter (27.65) was exhibited by the cluster v. The maximum cluster mean of 42.0 was observed for number of branches in cluster IV whereas the least cluster mean for number of branches (22.50) was exhibited by the cluster V. The maximum cluster mean of 2.65 was observed for bole height in cluster IV whereas the least cluster mean for bole height (2.17) was exhibited by the cluster V. The maximum cluster mean of 3.65 was observed for crown length in cluster III whereas the least cluster mean for crown length (1.71) was exhibited by the cluster V. In case of volume, the cluster mean was highest for cluster IV (0.050) and the lowest for cluster V (0.014). In general, the cluster IV and cluster $\mathrm{V}$ had highest and lowest mean values for most of the traits respectively.

Table 5. Cluster mean values for biometric attributes.

\begin{tabular}{lrrrrrrr}
\hline $\begin{array}{l}\text { Cluster/ } \\
\text { Character }\end{array}$ & $\begin{array}{r}\text { Tree } \\
\text { height }\end{array}$ & $\begin{array}{r}\text { Diameter } \\
\text { at breast } \\
\text { height }\end{array}$ & $\begin{array}{r}\text { Basal } \\
\text { diameter }\end{array}$ & $\begin{array}{r}\text { Number of } \\
\text { branches }\end{array}$ & $\begin{array}{r}\text { Clear bole } \\
\text { height }\end{array}$ & $\begin{array}{r}\text { Crown } \\
\text { height }\end{array}$ & Volume \\
\hline I & 5.35 & 26.55 & 41.34 & 30.28 & 2.25 & 3.10 & .032 \\
II & 5.62 & 27.49 & 40.01 & 34.46 & 2.29 & 3.32 & 0.037 \\
III & 5.88 & 32.42 & 46.00 & 37.91 & 2.22 & 3.65 & 0.042 \\
IV & 5.55 & 29.04 & 40.45 & 42.00 & 2.65 & 2.90 & 0.050 \\
V & 3.88 & 17.57 & 27.65 & 22.50 & 2.17 & 1.71 & 0.014 \\
\hline
\end{tabular}

Contribution of characters towards genetic divergence

The number of times each character ranking first was counted and percentage contribution towards divergence was calculated and presented in table 6. Volume contributed maximum percentage towards divergence $(36.84 \%)$ followed by bole height $(20.00 \%)$. Contribution towards divergence was not recorded by crown length $(0.00 \%)$.

Table 6. Percentage contributions of morphometric traits to genetic divergence.

\begin{tabular}{lrr}
\hline Character & No. of first rank & \% Contribution \\
\hline Tree height & 30 & 15.78 \\
DBH & 8 & 4.21 \\
Basal diameter & 35 & 18.42 \\
Number of branches & 9 & 4.73 \\
Bole Height & 38 & 20.00 \\
Crown length & 0 & 0.00 \\
Volume & 70 & 36.84 \\
\hline \multicolumn{1}{c}{ Total } & $\mathbf{1 9 0}$ & $\mathbf{1 0 0}$ \\
\hline
\end{tabular}

\section{DISCUSSION AND CONCLUSION}

\section{Genetic divergence}

Proper genetic resources and sufficient genetic divergence between the population is used in successful tree improvement programmes. Precise information on the nature and degree of genetic divergence in respect of important traits is a pre-requisite for undertaking meaningful breeding programme (Chaturvedi \& Pandey 2001) towards the improvement and conservation of a species (Ayad et al. 1995, Gradual et al. 1999). Assessment of genetic divergence in the populations of a species is of paramount significance in the purposeful breeding programme. The nature and degree of genetic divergence in the seed sources is useful for classifying them into groups on the basis of their diversity, particularly when overlapping for one or more characters is frequent, the genetic divergence analysis also helps in identifying the desirable genotypes for improvement programme, presuming that genetic diversity would provide greater livelihood of promising genetic rearrangement. In the current study, genetic diversity existed among the 20 selected progenies of Neolamarckia cadamba had been assessed through $\mathrm{D}^{2}$ analysis which resolved the 20 progenies in to five clusters.

\section{Cluster composition}

Diversity analysis provides in formation on deciding the choice of parents from distantly related cluster to www.tropicalplantresearch.com 
secure yield improvement in Neolamarckia cadamba. Clustering methods have the goal of separating a pool of observations in many subgroups to obtain homogeneity within and between the formed subgroups. $\mathrm{D}^{2}$ statistics is an important tool in plant breeding for estimating genetic divergence (Aslam et al. 2011). The exploitation of heterosis and success in getting desirable segregates in a breeding programme, largely depends on the degree of divergence in a chosen population (Paramathma \& Surendran 2000a). Genetic diversity is essential to meet the diversified goals of tree breeding such as breeding for cultivation, increasing yield, wider adaptation, desirable quality, pest and disease resistance. The extent of diversity that existed within the selected genotypes has been estimated using genetic divergence analysis (Mondal 2003).

Application of Mahalanobis statistics and Tocher's technique allowed grouping of the 20 Neolamarckia cadamba progenies into five distinct clusters (Fig. 1), indicating adequate genetic variability among the clusters under study. Among the five clusters, cluster I included a maximum of eight genotypes and cluster II and III included six and four respectively. The cluster IV and V included only a particularly unique and distinct genotype. In Pinus wallichiana, 88 plus tree progenies were grouped into 10 distinct clusters on the basis of Mahalanobis $\mathrm{D}^{2}$ statistic. Maximum number of genotypes (21) was grouped in cluster IV, followed by cluster III (18) and cluster X (14). Clusters V and VII consisted of 10 genotypes each followed by clusters I and VIII which included 8 and 4 genotypes, respectively. Cluster III, VI and IX were distinct and unique from others as each included only one genotype (Aslam et al. 2011). Similarly, 80 batches of teak had been grouped into eight clusters, of which group A formed the largest cluster containing 46 batches (Bagchi 2000).

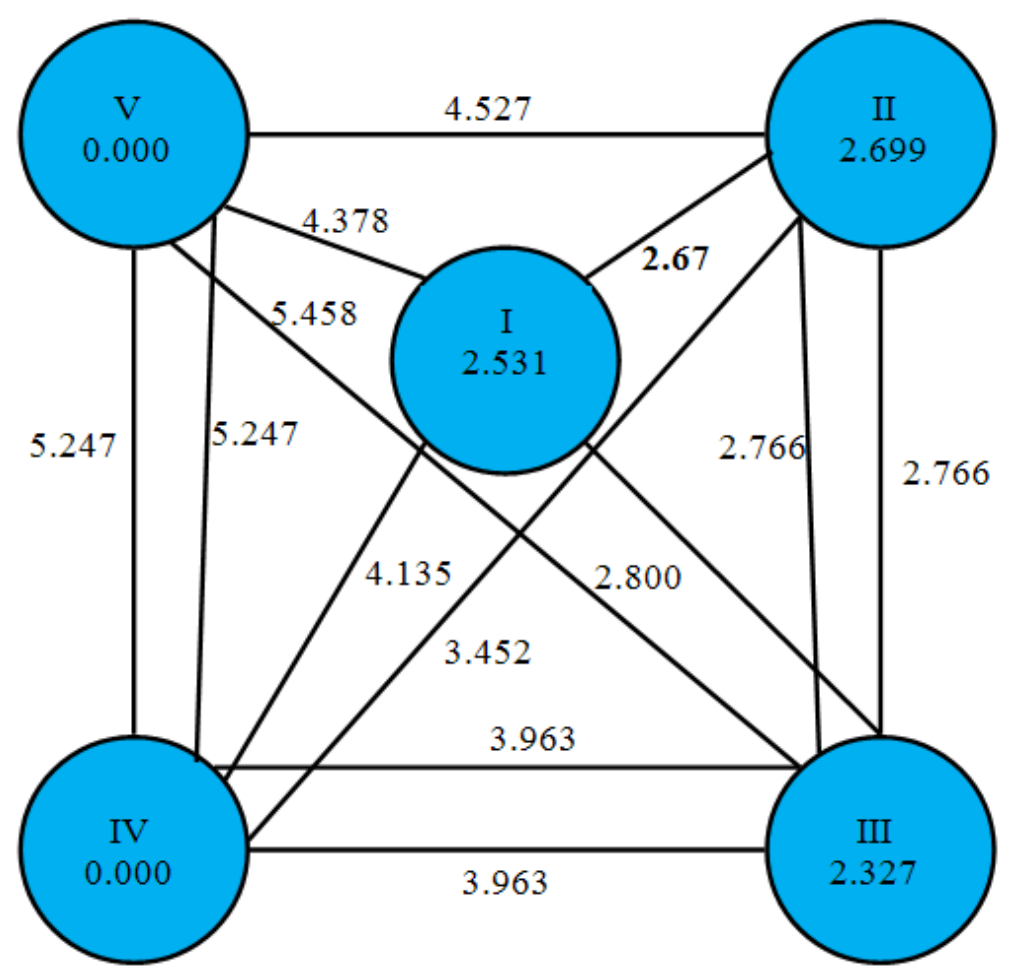

Figure 1. Cluster diagram for biometric traits of Neolamarckia cadamba progenies.

In the present investigation, some clusters included genotypes from all the locations, while others included only a particularly unique and distinct genotype. It could be seen that the genotypes from different locations grouped together to form a single major cluster as evident in cluster I and therefore the pattern of divergence was not depended on the geographic locations. These findings were in agreement with the results of Sagwal (1982), Khosla et al. (1994), Sehgal et al. (1994) in Pinus roxburghii; Arun Prasad et al. (1996) in Tectona grandis and Aslam et al. (2011) in Pinus wallichiana and suggested that all the genotypes from a given area may not necessarily form a single cluster. Thus, the pattern of divergence is not dependent on the geographical nearness of the genotypes and such a pattern could be attributed to differences in the genetic makeup of the otherwise co-occurring genotypes (Chauhan \& Sehgal 2001). The occurrence of genotypes from geographically different areas in the same cluster, as evidenced in the current study and also reported in Pungam which indicated that factors other than geographical nearness are also contributing towards genetic divergence (Kumaran 1991). 


\section{Intra and inter cluster average distance}

In the present study, the highest intra-cluster distance was observed for the cluster II (7.28) and the minimum for the cluster III (5.413). Cluster III has the minimum intra-cluster value indicating that genotype within the cluster was similar, while cluster II showed the maximum intra-cluster $\mathrm{D}^{2}$ value followed by cluster I (6.41) revealing the existence of diverse genotypes that fell in these clusters. The intra-cluster distance was much lower than inter-cluster one, suggested heterogeneous and homogenous nature between and within cluster respectively and also indicated wide genetic diversity among the genotypes of different clusters than those of the same cluster. The data on inter cluster distances and as per the performance of genotypes were used to select genetically diverse and silviculturally superior genotypes. The genotypes, exceptionally good with respect to one or more characters were desirable. A perusal of intra and inter-cluster distances revealed that highest intercluster distance of 29.79 between cluster III and V followed by cluster IV and V (27.52). If genotypes drawn from such genetically diverse clusters, they could be of particular significance in the production of high heterotic effect during hybridization (Singh \& Singh 1981, Aslam et al. 2011). Such inter and intra cluster distance among Pinus gerardiana was also reported which support the results of current conclusion (Kant et al. 2006).

\section{Cluster mean performance}

The data revealed considerable differences among the clusters for most of the characters studied. The cluster III recorded higher tree height, DBH, basal diameter and crown length. In respect of different biometric parameters considered in the present study, the clusters did vary (Table 5) and such variations in cluster means have also been reported by Aslam et al (2011) in Pinus wallichiana, Kumaran (1997) in Neem and Bagchi (2000) in Tectona grandis. Surendran \& Chandersekhran (1988) studied the genetic divergence among half-sib progenies of 35 single tree selections of Eucalyptus tereticornis from different agro-climatic zones of Tamil Nadu at 24 month growth phase and identified promising clusters for their use in the silvicultural management of the species. Genetic diversity is the outcome of several factors, including topographical diversification. Therefore, selection of genotypes of higher productivity should be based on genetic diversity rather than geographic diversity (Singh 1993).

\section{Contribution of traits towards genetic divergence}

In the present investigation, among the growth attributes, volume contributed maximum (36.84\%) towards genetic divergence followed by bole height, basal diameter, tree height, number of branches and DBH. Paramathma (1992) reported similar results in six Eucalyptus species and twelve interspecific hybrids; Bagchi (2000) in Tectona grandis; Tikader (2001) in Morus species; Manga \& Sen (2000) in Prosopis cineraria; Tewari et al. (2002) in Dalbergia sissoo; Chauhan \& Sehgal (2001) in Pinus roxburghii and Vennila (2009) in Eucalyptus also reported contribution of volume index along with other morphometric traits towards genetic divergence among the genotypes tested which might be due to the existence of broader genetic base. Based on the previous work and the current finding, the contributions of volume index for genetic divergence indicated that this derived factor could be used as an index for Neolamarckia cadamba tree improvement programme.

The findings of the present study are also in line with the results of Burley \& Burrows (1972), who employed multivariate analysis in Pinus kesiya and suggested that, this techniques mainly used to identify the best progenies among the different genetic resources through many number of clusters and the selected superior cluster are used to afforestation and reforestation programmes. Hopefully such knowledge will aid propagators, geneticists, breeder and tree improvement specialists in enhancing the quality and productivity of the forest ecosystems to meet their market demand. Notwithstanding the differences, the present study clearly establishes the superiority of cluster III recommends propagation of material from the trees belonging to this cluster for utilization in immediate plantation programmes for better productivity of the species.

\section{ACKNOWLODGEMENTS}

The authors profusely thank to Forest College and Research Institute, Tamil Nadu Agricultural University, Mettupalayam for conducting research trials.

\section{REFERENCE}

Kant A, Dutt V \& Sharma DR (2006) Genetic variability in phenotypic characters of Pinus gerardiana. Indian Forester 345: 681-690. 
Arun Prasad KCA (1996) Variability studies in teak (Tectona grandis Linn. F.), M.Sc. Thesis. Tamil Nadu Agricultural University, Coimbatore, India.

Aslam MA, Zafar R \& Siddiqi TO (2011) Genetic divergence in half-sib progenies of Pinus wallichiana A.B. Jackson plus trees in the Kashmir Himalaya, India. Tropical Ecology 52(2): 201-208.

Ayad W, Hodgkin G, Jaradat A \& Rao UR (1995) Molecular genetic techniques for plant genetic resources. IPGRI Report, $135 \mathrm{p}$.

Bagchi SK (2000) Genetic divergence in Tectona grandis. Annual Forester 8(1): 25-37.

Burley J \& Burrows PM (1972) Multivariate analysis of variation in needles among provenances of Pinus kesiya Royle ex Gordon (Syn, P. khasya Royle, and P. insularis Enlicher). Silvae Genetica 21: 69-77.

Chaturvedi OP \& Pandey N (2001) Genetic divergence in Bombax ceiba L. germplasms. Silvae Genetica 50: 99-102.

Chauhan SK \& Sehgal RN (2001) Genetic diversity among progenies of Himalayan long Pine. Indian Journal of Forestry 24(1): 65-71.

Gradual L, Kjaer ED, Suangtho P \& Kaosaard A (1999) Conservation of genetic resources of Teak (Tectona grandis) in Thailand. Technical Note No. 52, Danida Forest Seed Centre, Denmark.

Gregory PJ, Ingram JSI, Andersson R, Betts RA, Brovkin V \& Chase TN (2002) Environmental consequences of alternative practices for intensifying crop production. Agricultural Ecosystem Environment 88: 279-290.

Khosla PK (1994) Potential of economic utility of Pines. Proceedings of IUFRO group P.S.01, Manuas, Brazil, pp. $18-22$.

Kumaran K (1991) Genetic analysis of seed and juvenile seedling attributes in Neem (Azadirachta indica A. Juss) and Pungam [Pongamia pinnata (Linn.) Pierre.], M.Sc. Thesis. Tamil Nadu Agricultural University, Coimbatore.

Kumaran K (1997) Selection of one - parent families for higher growth, oil and Azadirachtin content in neem (Azadirachta indica A. Juss.), Ph.D. Thesis. Tamil Nadu Agricultural University, Coimbatore.

Lal P (2011) Clonal Agroforestry Plantations in India. Indian Journal of Ecology 38 (Special Issue): 6-10.

Mahalanobis PC (1928) On the generalized distance in statistics. In: Proceedings, National Institute of Science, India, pp. 49-55.

Manga VK \& Sen DN (2000) Genetic diversity among different genotypes of Prosopis cineraria Druce. Indian Journal of forestry 23(3): 291-295.

Martawijaya A, Kartasujana I, Mandang YI, Prawira SA \& Kadir K (1989) Atlas kayu Indonesia Jilid II. Pusat Penelitian dan Pengembangan Hasil Hutan, Bogor, Indonesia.

Mondal MAA (2003) Improvement of potato (Solanum tuberosum L.) through hybridization and in vitro culture technique, Ph.D Thesis. Rajshahi University, Rajshahi, Bangladesh.

Paramathma M (1992) Studies on genetic inheritance and interspecific crosses of Eucalyptus, Ph.D. Thesis. Tamil Nadu Agricultural University, Coimbatore.

Paramathma M \& Surendran C (2000) Exploitation of heterosis for afforestation in Eucalyptus. In: Proceeding of the International Symposium on Hybrid Breeding and Genetics, 9-14 April, Noose Lake, FRI, Australia.

Parthiban KT (2016) Tree Insurance-An Innovative Intervention in Industrial Agroforestry. Indian Forester 142(5): $1-11$

Rao CR (1952) Advanced statistical methods in biometrical research. John Wiley and Sons, New York. pp. 357-363.

Sagwal SS (1982) Estimation of genetic parameters in needle length of chir pine (Pinus roxburghii Sargent), Indian Journal of Forestry 5(3): 189-191.

Sehgal RN, Chauhan SK \& Dhall SP (1994) Half-sib progeny evaluation in chirpine. Silvae Genet 44(2): 61-62.

Singh NB (1993) Estimation of variance, heritability, genetic gain and correlations among growth characters in Bambusa pallida. Indian Journal of Forestry 16(1): 33-38.

Singh RB \& Singh SV (1981) Phenotypic stability and adaptability of durum and bread wheat for grain yield. Indian Journal of Genetics 40: 86-92.

Soerianegara I \& Lemmens RHMJ (1993) Plant resources of South-east Asia 5 (1): Timber trees: Major commercial timbers. Pudoc Scientific Publishers, Wageningen, Netherlands.

Surendran C \& Chandrasekaran P (1988) Genetic divergence among half sib progenies of Eucalyptus tereticornis Sm. In: Khosla PK \& Seghal RN (eds) Trends in Tree Sciences. ISTS, pp. 218-224. 
Tewari SK, Subhanjana AK \& Pandey SBS (2002) Genetic Divergence in Shisham (Dalbergia sissoo Roxb). Indian Journal of forestry 25(1): 21-24.

Tikader A (2001) Genetic Divergence Analysis in Mulberry Germplasm (Morus spp.). Indian Journal of Forestry 24(3): 328-331.

Vennila S (2009) Pulpwood traits, genetic and molecular characterization of Eucalyptus genetic resources, Ph.D thesis. Tamil Nadu Agricultural University, Coimbatore.

Zobel BJ (1981) Vegetative propagation in forest management operations. In: Proceeding $16^{\text {th }}$ South for Tree Improvement. Meet, Blacksburg, Virginia, pp. 149-159.

Zobel BJ (1971) The genetic improvement of Southern pines. Scientific American 225: 94-103.

Zobel BJ \& Talbert J (1984) Applied Tree Improvement. John Wiley and Co., 503 p. 